\title{
Comparing CB-SEM and PLS-SEM Results: An empirical example
}

\author{
Research-in-Progress
}

\author{
Suzanne Amaro \\ Polytechnic Institute of Viseu \\ samaro@estgv.ipv.pt \\ José Luís Abrantes \\ Polytechnic Institute of Viseu \\ jlabrantes@estgv.ipv.pt
}

Cláudia Seabra

Polytechnic Institute of Viseu

cseabra@estgv.ipv.pt

\begin{abstract}
Many scholars view PLS-SEM as less rigorous than CB-SEM, namely due to is less restrictive assumptions. The main objective of this research is to compare the results of both approaches, for a given model, to examine if there are, indeed, noteworthy differences. The study shows that the results obtained in both approaches are very similar. These findings provide useful insights to researchers.
\end{abstract}

Keywords: CB-SEM, Involvement, PLS-SEM, Risk Perception, Safety Concerns, Structural Equation Modelling, Terrorism 


\section{Introduction}

Structural Equation Modelling (SEM) has grown in academic research in a large number of academic disciplines (Gallagher, Ting, \& Palmer, 2008) and is considered as one of the most important statistical developments in social sciences in recent years (Hair, Ringle, \& Sarstedt, 2012). Without doubt, SEM presents several characteristics that have attracted researchers and set it apart from first generation regression tools (e.g. linear regression, analysis of variance [ANOVA] and multivariate analysis of variance [MANOVA]). In particular, research questions can be answered in a single, systematic and comprehensive analysis by modelling the relationships among multiple independent and dependent constructs (the structural model) simultaneously (Gefen, Straub, \& Boudreau, 2000; Hair, Black, Babin, \& Anderson, 2010). Moreover, in the same analysis, SEM not only assesses the structural model but also evaluates the measurement model (Gefen, Rigdon, \& Straub, 2011; Gefen et al., 2000). This combined analysis enables measurement errors of the observed variables to be analysed as an integral part of the model (Gefen et al., 2000), which makes the estimates provided by SEM better than those produced by linear regression (Gefen et al., 2011).

Researchers applying SEM can choose between a covariance base analysis (CB-SEM) or a variance based approach, known as partial least squares (PLS-SEM) (Gefen et al., 2000; Hair, Sarstedt, Ringle, \& Mena, 2012). Each approach has different assumptions and aims. The CB-SEM approach aims at reproducing the theoretical covariance matrix, without focusing on explained variance, while PLS-SEM aims at maximizing the explained variance of the dependent constructs (Hair, Ringle, et al., 2012). PLS-SEM has less restrictive assumptions than CB-SEM and that is one of the reasons why many scholars view it as less suitable (Hair, Ringle, \& Sarstedt, 2011). The main objective of this research is to examine if there are noteworthy differences between the two approaches. Research on comparisons between statistical techniques is valuable to researchers to have guidance about which statistical technique could be more useful and valuable for their research (Goodhue, Lewis and Thompson, 2012).

\section{Empirical example}

\subsection{Conceptual Framework}

In order to compare CB-SEM and PLS-SEM, a model applied in a previous study using CB-SEM conducted by Seabra et al. (2014) was used. Their model examines the influence of terrorism risk on purchase involvement and safety concern of international travellers. The final model has four constructs: Interest and Attention in Terrorism, Risk Perceptions in International Trips, Safety Importance and Involvement (with the decision to purchase the product). The following hypotheses were examined and confirmed:

H1: Higher interest and attention to terrorism in the media by tourists increases their involvement in the buying decision.

$\mathrm{H} 2$ : Higher interest and attention to terrorism in the media by tourists increases their risk perception in international travel.

H3: Higher interest and attention to terrorism in the media by tourists increases safety importance.

H4: Higher risk perceptions in international travel by tourists increases their involvement in the buying decision. 
H5: Higher risk involvement in the buying decision increases safety importance.

The conceptual model and hypotheses is exhibited in Figure 1.

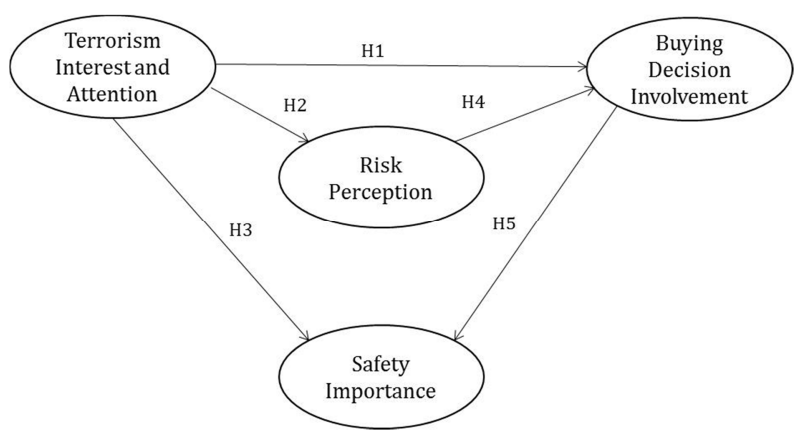

Figure 1: Conceptual Model and Hypotheses

The scales used for the self-administered questionnaires were selected from literature and discussed with experts (see Table 1). The questionnaire was pre-tested before being applied at three international airports: Madrid, Lisbon and Milan. A total of 200 valid questionnaires from each airport were obtained.

Table 1 - Constructs' Indicators

\begin{tabular}{|c|c|}
\hline Construct & Indicators \\
\hline \multirow{6}{*}{$\begin{array}{l}\text { Attention and Interest } \\
\text { in Terrorism in Media }\end{array}$} & V1- I am really interested about terrorist attacks reports on news \\
\hline & V2 - When I have the opportunity I watch/read/ear reports about terrorist attacks on news \\
\hline & V3 - I am very curious about terrorist attacks reports on news \\
\hline & V4 - I do not want to miss terrorist attacks reports on news \\
\hline & V5 - I never want to change the channel during a report of terrorist attack on news \\
\hline & V6 - I pay much attention on reports about terrorist attacks on news \\
\hline \multirow{6}{*}{ Risk Perception } & V7 - Possibility of physical danger or injury detrimental to healt (accidents) \\
\hline & V8 - Possibility of becoming involved in the political turmoil of the country being visited \\
\hline & $\begin{array}{l}\text { V9 - Possibility that travel experience will not reflect the individual's personality or self- } \\
\text { image }\end{array}$ \\
\hline & V10 - Possibility that travel experience will not provide personal satisfaction \\
\hline & V11 - Possibility that travel choice/experience will afect other's opinion of individual \\
\hline & V12 - Possibility of being involved in a terrorist act \\
\hline \multirow{12}{*}{$\begin{array}{l}\text { Involvement } \\
\text { (importance of the } \\
\text { information sources) }\end{array}$} & V13 - Advertising on TV, radio or press (primary decisions) \\
\hline & V14 - Brochures (primary decisions) \\
\hline & V15 - Virtual Visits (primary decisions) \\
\hline & V16 - Travel Agents (primary decisions) \\
\hline & V17 - Travel Clubs/books/magazines (primary decisions) \\
\hline & V18 - Reports in TV, radio, press (primary decisions) \\
\hline & V19 - Welcome Centres (primary decisions) \\
\hline & V20 - Advertising on TV, radio or press (secondary decisions) \\
\hline & V21 - Internet Forums (secondary decisions) \\
\hline & V22 - Virtual Visits (secondary decisions) \\
\hline & V23 - Travel Agents (secondary decisions) \\
\hline & V24 - Reports in TV, radio, press (secondary decisions) \\
\hline \multirow{3}{*}{ Safety Importance } & V25 - Additional security measures at airports make traveling safer \\
\hline & V26 - Safety is the most important attribute a destination can offer \\
\hline & V27 - Safety is a serious consideration when I am choosing a destination \\
\hline
\end{tabular}

\subsection{Model Assessment}

In the CB-SEM approach conducted in the study of Seabra et al. (2014), the items were subjected to a confirmatory factor analysis using full-information maximum likelihood (FIML) estimation procedures in Lisrel 8.54 to assess the validity of the measures (Jöreskog \& Sörbom, 1996). In the PLS-SEM approach, the first part in evaluating a model is to 
present the outer model results to examine the reliability and validity of the measures used to represent each construct (Chin, 2010). In the current study this was done using SmartPLS 2.0 (Ringle, Wende, \& Will, 2005).

As Goodhue et al. (2012) point out, regardless of the choice of the statistical technique, researchers have the same objectives: (1) to ensure that the measurement model is adequate (in terms of reliability and validity), (2) to generate estimates of the strengths of the paths in the structural model, and (3) to determine the statistical significance of those path estimates.

The assessment of the constructs involves determining indicator reliability, internal consistency reliability, convergent validity and discriminant validity, as described by Hair et al. (2011), Hair, Sarstedt, et al. (2012) and Henseler, Ringle, and Sinkovics (2009). Table 2 resumes the measures obtained in both approaches.

Table 2 - Reliability and Convergent Validity Measures

\begin{tabular}{|c|c|c|c|c|c|c|c|c|c|}
\hline \multirow[b]{2}{*}{ Construct } & \multirow[b]{2}{*}{ Indicator } & \multicolumn{2}{|c|}{ Indicator loadings } & \multicolumn{2}{|c|}{ Cronbach Alpha } & \multicolumn{2}{|c|}{ Composite Reliability } & \multicolumn{2}{|c|}{ AVE } \\
\hline & & $\begin{array}{l}\text { CB- } \\
\text { SEM }\end{array}$ & $\begin{array}{l}\text { PLS - } \\
\text { SEM }\end{array}$ & $\begin{array}{l}\text { CB- } \\
\text { SEM }\end{array}$ & $\begin{array}{l}\text { PLS } \\
\text { SEM }\end{array}$ & $\begin{array}{l}\text { CB- } \\
\text { SEM }\end{array}$ & $\begin{array}{l}\text { PLS - } \\
\text { SEM }\end{array}$ & $\begin{array}{l}\text { CB- } \\
\text { SEM }\end{array}$ & $\begin{array}{l}\text { PLS - } \\
\text { SEM }\end{array}$ \\
\hline \multirow{6}{*}{$\begin{array}{l}\text { Attention and } \\
\text { Interest in } \\
\text { Terrorism in } \\
\text { Media }\end{array}$} & V1 & 0.86 & 0.87 & \multirow{6}{*}{\multicolumn{2}{|c|}{0.95}} & \multirow{6}{*}{0.95} & \multirow{6}{*}{0.96} & \multirow{6}{*}{0.75} & \multirow{6}{*}{0.79} \\
\hline & $\mathrm{V} 2$ & 0.92 & 0.91 & & & & & & \\
\hline & $\mathrm{V} 3$ & 0.92 & 0.91 & & & & & & \\
\hline & V4 & 0.86 & 0.89 & & & & & & \\
\hline & V5 & 0.75 & 0.82 & & & & & & \\
\hline & V6 & 0.87 & 0.92 & & & & & & \\
\hline \multirow{6}{*}{ Risk Perception } & V7 & 0.65 & 0.72 & \multirow{6}{*}{\multicolumn{2}{|c|}{0.85}} & \multirow{6}{*}{0.86} & \multirow{6}{*}{0.89} & \multirow{6}{*}{0.50} & \multirow{6}{*}{0.58} \\
\hline & V8 & 0.73 & 0.80 & & & & & & \\
\hline & V9 & 0.76 & 0.79 & & & & & & \\
\hline & V10 & 0.73 & 0.76 & & & & & & \\
\hline & V11 & 0.71 & 0.76 & & & & & & \\
\hline & V12 & 0.65 & 0.75 & & & & & & \\
\hline \multirow{12}{*}{$\begin{array}{l}\text { Involvement } \\
\text { (importance of } \\
\text { the information } \\
\text { sources) }\end{array}$} & V13 & 0.66 & 0.74 & \multirow{12}{*}{\multicolumn{2}{|c|}{0.92}} & \multirow{12}{*}{0.92} & \multirow{12}{*}{0.93} & \multirow{12}{*}{0.50} & \multirow{12}{*}{0.53} \\
\hline & V14 & 0.63 & 0.70 & & & & & & \\
\hline & V15 & 0.73 & 0.74 & & & & & & \\
\hline & V16 & 0.68 & 0.73 & & & & & & \\
\hline & V17 & 0.64 & 0.66 & & & & & & \\
\hline & V18 & 0.77 & 0.79 & & & & & & \\
\hline & V19 & 0.69 & 0.71 & & & & & & \\
\hline & V20 & 0.66 & 0.72 & & & & & & \\
\hline & V21 & 0.68 & 0.67 & & & & & & \\
\hline & V22 & 0.78 & 0.77 & & & & & & \\
\hline & V23 & 0.72 & 0.75 & & & & & & \\
\hline & V24 & 0.8 & 0.79 & & & & & & \\
\hline \multirow{3}{*}{ Safety Importance } & V25 & 0.69 & 0.81 & \multirow{3}{*}{\multicolumn{2}{|c|}{0.81}} & \multirow{3}{*}{0.81} & \multirow{3}{*}{0.88} & \multirow{3}{*}{0.60} & \multirow{3}{*}{0.72} \\
\hline & V26 & 0.86 & 0.88 & & & & & & \\
\hline & V27 & 0.76 & 0.85 & & & & & & \\
\hline
\end{tabular}

In both approaches, internal consistency was evidenced by the composite reliability and Cronbach alphas scores. Indeed, all are above the recommended value of 0.7 (Hair et al., 2011). While the Cronbach's alphas are identical in both approaches, since it uses the correlations of the indicators, the composite reliability values are higher when using PLSSEM.

To assess convergent validity, the average variance extracted (AVE) was measured. It is recommended that the AVE should be above 0.5 (Fornell \& Larcker, 1981). In both approaches, the AVEs are above this cut off point, confirming convergent validity. However, in the CB-SEM approach, two constructs have an AVE of 0.5, whereas in the PLS-SEM approached the values are slightly higher.

Discriminant validity was assessed for using the two measures that are typically used: the Fornell-Larcker criterion and the cross loadings (Henseler et al., 2009). According to the 
former construct, the AVE of each construct should be higher than the squared correlations with all other constructs (Fornell \& Larcker, 1981). The results presented in Table 3 confirm discriminant validity in both approaches to SEM, since the square root of each construct's AVE is larger than its correlations with any other construct and indicators loaded more highly on the construct it is supposed to measure. Both approaches produce similar values.

Table 3 - Correlations among constructs

\begin{tabular}{lcccc}
\hline \multicolumn{1}{c}{ CB-SEM } & 1 & 2 & 3 & 4 \\
\hline 1 - Interest and Attention in Terrorism & $\mathbf{0 . 8 7}$ & & & \\
2 - Risk Perception & 0.26 & $\mathbf{0 . 7 1}$ & & \\
3 - Safety Importance & 0.38 & 0.17 & $\mathbf{0 . 7 7}$ & \\
4 - Involvement (buying decision) & 0.18 & 0.29 & 0.21 & $\mathbf{0 . 7 1}$ \\
\hline \multicolumn{1}{c}{ PLS-SEM } & & & 3 \\
\hline 1 - Interest and Attention in Terrorism & $\mathbf{0 . 8 9}$ & 2 & & \\
2 - Risk Perception & 0.25 & $\mathbf{0 . 7 6}$ & & \\
3 - Safety Importance & 0.36 & 0.14 & $\mathbf{0 . 8 5}$ & $\mathbf{0 . 7 3}$ \\
4- Involvement (buying decision) & 0.19 & 0.28 & 0.19 &
\end{tabular}

Discriminant validity was also confirmed since the indicators loaded more highly on the construct it is supposed to measure (values not shown). Once again, in both approaches the values obtained were very similar.

The estimation of the path coefficients in both approaches are presented in Table 4. All hypotheses were supported, regardless of the method used. Excluding the path coefficient between terrorism interest and attention -> Buying decision Involvement, the path coefficients obtained in the CB-SEM approach are slightly higher.

Table 4 - Hypotheses Tests Results

\begin{tabular}{lcccc}
\hline \multicolumn{1}{c}{ Hypotheses } & \multicolumn{2}{c}{ CB-SEM } & \multicolumn{2}{c}{ PLS-SEM } \\
\hline & $\begin{array}{c}\text { Path } \\
\text { Coefficient }\end{array}$ & t-Value & $\begin{array}{c}\text { Path } \\
\text { Coefficient }\end{array}$ & t-Value \\
\hline $\begin{array}{l}\text { H1: Terrorism Interest and Attention -> } \\
\text { Buying Decision Involvement }\end{array}$ & 0.11 & $2.47^{* * *}$ & 0.13 & $3.01^{* * *}$ \\
\hline $\begin{array}{l}\text { H2: Terrorism Interest and Attention -> } \\
\text { Risk Perception }\end{array}$ & 0.26 & $5.59^{* * *}$ & 0.25 & $6.12^{* * *}$ \\
\hline $\begin{array}{l}\text { H3: Terrorism Interest and Attention -> } \\
\text { Safety Importance }\end{array}$ & 0.36 & $7.56^{* * *}$ & 0.34 & $8.48^{* * *}$ \\
\hline $\begin{array}{l}\text { H4: Risk Perception -> Buying } \\
\text { Decision Involvement }\end{array}$ & 0.27 & $5.38^{* * *}$ & 0.25 & $5.89^{* * *}$ \\
\hline $\begin{array}{l}\text { H5: Buying Decision Involvement -> } \\
\text { Safety Importance }\end{array}$ & 0.15 & $3.23^{* * *}$ & 0.13 & $3.50^{* * *}$ \\
\hline$* * *$ Significant at 0.001 level & & & & \\
\hline
\end{tabular}

In the CB-SEM approach, the model has a chi-square of 1925.78 and the fit indices suggest a good fit of the model to the data $(\mathrm{CFI}=0.92$, IFI=0.92, TLI=0.91, RMSEA=0.92, GFI=0,81, AGFI=0.77 and PGFI=0.68). The classic measures for CB-SEM are not applicable in PLS-SEM (Hair, Sarstedt, et al., 2012) and therefore researchers must focus their evaluation on other criteria to assess the inner model, such as predictive relevance $\left(Q^{2}\right)$ and effect size. If $Q^{2}>0$, the model has predictive relevance, whereas $Q^{2}<0$ represents a lack of predictive relevance (Chin, 2010). The predictive relevance of the dependent variables in the model were higher than zero. Yet, it should be noted that the values were low $($ Risk Perception $=0.03$; Involvement $=0.05$ and Safety Importance $=0.10$ ). 


\section{Conclusions}

The results obtained in this study demonstrate that both approaches produce similar results. In an earlier study, Reinartz, Haenlein and Henseler (2009) had already pointed out to the fact that both approaches achieved comparable results, especially when the models have good measurement proprieties. In this study, PLS-SEM produced higher Reliability and Convergent Validity Measures, while CB-SEM achieved higher path coefficients.

However, one must be cautious in interpreting the results. Indeed, for another model, with a smaller sample size, for example, the results obtained could differ. Goodhue et al. (2012) stress that when drawing conclusions in comparing approaches there is always the concern that the differences (or not) may be due to random peculiarities of the dataset used.

One of the major limitations of this study is the fact that Seabra et al.'s (2014) final model was used to compare both methods. Indeed, their initial model has more constructs and items. Therefore, it would be noteworthy to compare CB-SEM and PLS-SEM with the initial model as a basis. In fact, the researchers intend to continue the comparison and this will be considered in future work. Despite this study's limitations, it provides useful arguments in the debate PLS-SEM or CB-SEM.

\section{Acknowledgements}

The authors would like to thank the Polytechnic Institute of Viseu, the Center for Studies in Education, Technologies and Health (CI\&DETS) and the Portuguese Foundation for Science and Technology (FCT).

\section{References}

Chin, W. W. (2010). How to Write Up and Report PLS Analyses. In V. E. Vinzi, W. W. Chin, J. Henseler \& H. Wang (Eds.), Handbook of Partial Least Squares: Concepts, Methods and Applications in Marketing and Related Fields (pp. 655-690). Berlin: Springer.

Fornell, C., \& Larcker, D. F. (1981). Evaluating Structural Equation Models with Unobservable Variables and Measurement Error. Journal of Marketing Research, 18(1), 39-50.

Gallagher, D., Ting, L., \& Palmer, A. (2008). A journey into the unknown; taking the fear out of structural equation modeling with AMOS for the first-time user. The Marketing Review, 8(3), 255-275.

Gefen, D., Rigdon, E. E., \& Straub, D. (2011). An Update and Extension to SEM Guidelines for Administrative and Social Science Research. MIS Quarterly, 35(2), III-XIV.

Gefen, D., Straub, D. W., \& Boudreau, M.-C. (2000). Structural Equation Modeling and Regression Guidelines for Research Practice. Communications of the Association for Information Systems, 4(7), 2-77.

Goodhue, D. L., Lewis, W., \& Thompson, R. (2012). Comparing PLS to regression and LISREL: A response to Marcoulides, Chin, and Saunders. MIS Quarterly, 36(3), 703-716.

Hair, J. F., Black, W. C., Babin, H. J., \& Anderson, R. E. (2010). Multivariate Data Analysis (7th ed.). New Jersey: Prentice Hall.

Hair, J. F., Ringle, C. M., \& Sarstedt, M. (2011). PLS-SEM: Indeed a silver bullet. Journal of Marketing Theory and Practice, 19(2), 139-151.

Hair, J. F., Ringle, C. M., \& Sarstedt, M. (2012). Partial Least Squares: The Better Approach to Structural Equation Modeling? Long Range Planning, 45(5-6), 312-319. 
Hair, J. F., Sarstedt, M., Ringle, C. M., \& Mena, J. A. (2012). An assessment of the use of partial least squares structural equation modeling in marketing research. Journal of the Academy of Marketing Science, 40(3), 414-433.

Henseler, J., Ringle, C. M., \& Sinkovics, R. R. (2009). The use of Partial Least Squares Path Modeling in International Marketing. Advances in International Marketing, 20, $277-$ 319.

Jöreskog, K.G. \& Sörbom, D. (1996). LISREL 8: User's Reference Guide. Chicago, IL: Scientific Software International.

Reinartz, W., Haenlein, M., \& Henseler, J. (2009). An empirical comparison of the efficacy of covariance-based and variance-based SEM. International Journal of research in Marketing, 26(4), 332-344.

Ringle, C. M., Wende, S., \& Will, S. (2005). SmartPLS 2.0 (M3) (Version Beta). [Software]. Hamburg. Retrieved from http://www.smartpls.de

Seabra, C., Abrantes, J.L. \& Kastenholz, E. (2014).The influence of terrorism risk perception on purchase involvement and safety concern of international travellers. Journal of Marketing Management. 30 (9-10), 874-903. 